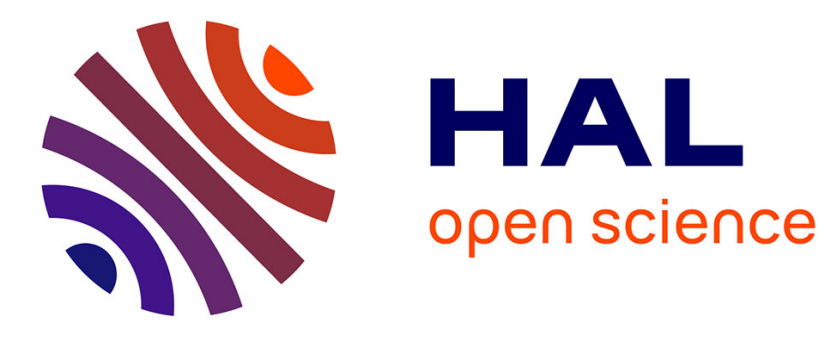

\title{
Generation and characterization of T40/A5754 interfaces with lasers
}

\author{
Patrice Peyre, Laurent Berthe, Morgan Dal, Sébastien Pouzet, Pierre \\ Sallamand, Iryna Tomashchuk
}

\section{- To cite this version:}

Patrice Peyre, Laurent Berthe, Morgan Dal, Sébastien Pouzet, Pierre Sallamand, et al.. Generation and characterization of T40/A5754 interfaces with lasers. Journal of Materials Processing Technology, 2014, 214, pp.1946-1953. 10.1016/j.jmatprotec.2014.04.019 . hal-01023673

\section{HAL Id: hal-01023673 https://hal.science/hal-01023673}

Submitted on 15 Jul 2014

HAL is a multi-disciplinary open access archive for the deposit and dissemination of scientific research documents, whether they are published or not. The documents may come from teaching and research institutions in France or abroad, or from public or private research centers.
L'archive ouverte pluridisciplinaire HAL, est destinée au dépôt et à la diffusion de documents scientifiques de niveau recherche, publiés ou non, émanant des établissements d'enseignement et de recherche français ou étrangers, des laboratoires publics ou privés. 


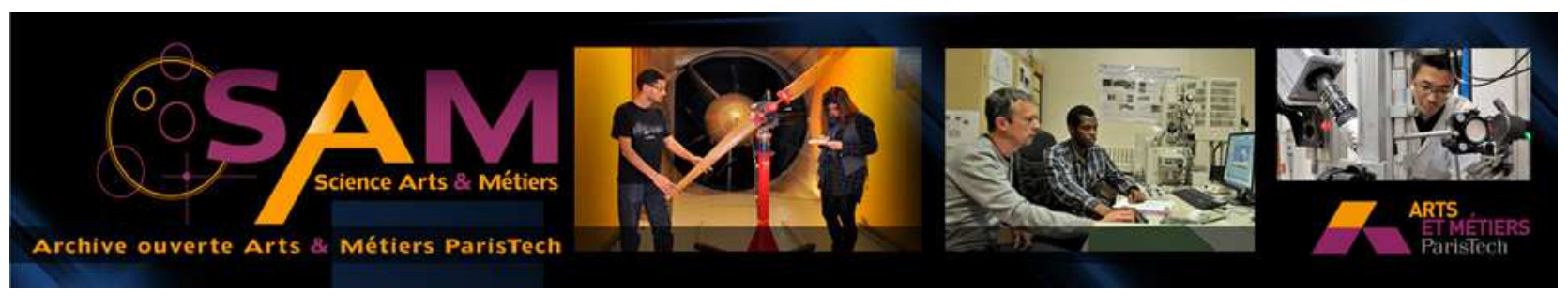

\section{Science Arts \& Métiers (SAM)}

is an open access repository that collects the work of Arts et Métiers ParisTech researchers and makes it freely available over the web where possible.

This is an author-deposited version published in: http://sam.ensam.eu

Handle ID: .http://hdl.handle.net/10985/8354

\section{To cite this version :}

Patrice PEYRE, Laurent BERTHE, Morgan DAL, Sébastien POUZET, Pierre SALLAMAND, Iryna TOMASHCHUK - Generation and characterization of T40/A5754 interfaces with lasersPatrice Journal of Materials Processing Technology - Vol. 214, p.1946-1953 - 2014 


\title{
Generation and characterization of T40/A5754 interfaces with lasers
}

\author{
Patrice Peyre ${ }^{\mathrm{a}, *}$, Laurent Berthe ${ }^{\mathrm{a}}$, Morgan Dal $^{\mathrm{a}}$, Sébastien Pouzet ${ }^{\mathrm{a}}$, Pierre Sallamand ${ }^{\mathrm{b}}$, \\ Iryna Tomashchuk ${ }^{\mathrm{b}}$ \\ a PIMM Laboratory, UMR 8006 CNRS - Arts et Métiers ParisTech, 151 Bd de l'Hôpital, 75013 Paris, France \\ ${ }^{\mathrm{b}}$ LTM - ICB Laboratory, UMR 6303 CNRS - Université de Bourgogne, 12 rue de la fonderie, 71200 Le Creusot, France
}

\begin{abstract}
A B S T R A C T
Laser-induced reactive wetting and brazing of T40 titanium with A5754 aluminum alloy with $1.5 \mathrm{~mm}$ thickness was carried out in lap-joint configuration, with or without the use of Al5Si filler wire. A $2.4 \mathrm{~mm}$ diameter laser spot was positioned on the aluminum side to provoke spreading and wetting of the lower titanium sheet, with relatively low scanning speeds $(0.1-0.6 \mathrm{~m} / \mathrm{min})$. Process conditions did not play a very significant role on mechanical strengths, which were shown to reach $250-300 \mathrm{~N} / \mathrm{mm}$ on a large range of laser power and scanning speeds. In all cases considered, the fracture during tensile testing occurred next to the $\mathrm{TiAl}_{3}$ interface, but in the aluminum fusion zone. The interfacial resistance was then evaluated with the LASAT bond strength tester, based upon the generation and propagation of laser-induced shock waves. A $0.68 \mathrm{GPa}$ uniaxial bond strength was estimated for the T40/A5754 interface under dynamic loading conditions.
\end{abstract}

Keywords:

Dissimilar joining

Laser

Shock waves

Titanium

Aluminum

\section{Introduction}

The dissimilar joining of titanium and aluminum, despite many potential applications in several industries, is usually restrained by the bad metallurgical compatibility of the two materials, which exhibit a limited solubility of titanium in aluminum solid solution and the extensive formation of brittle intermetallic compounds such as $\mathrm{TiAl}_{3}$ as indicated by Gupta (2003). This was particularly true when joining was carried out in liquid regime which promotes Ti-Al inter-diffusion. For this reason, many recent investigations like Chen and Nakata (2009) or Liao et al. (2010) have considered Ti-Al joining at a solid state with friction stir welding. Similarly, Kahraman et al. (2007) have carried out successfully explosive bonding assemblies without fusion of the metals. Other trials have used brazing processes where the titanium side is kept solid whereas only the aluminum side is molten. For instance, Chen et al. (2009) have proposed a specific Y-shape configuration for assembling Ti6Al4V and Al6Mg alloy with laser in welding-brazing regime whereas Ma et al. (2013) have carried out tungsten arc butt-joining with $\mathrm{Al}-\mathrm{Si}$ filler wire. Considering brazing processes, many factors need to be addressed: (1) some of them concern the wettability of titanium by liquid aluminum pools and the potential influence of non-melted $\mathrm{Al}_{2} \mathrm{O}_{3}$ oxides floating on the spreading

\footnotetext{
* Corresponding author. Tel.: +33171936544.

E-mail address: patrice.peyre@ensam.eu (P. Peyre).
}

melt-pools, (2) other ones come from the influence of the $\mathrm{TiAl}_{3}$ interfacial layer thickness on final mechanical resistance. Preliminary investigations like those by Chen et al. (2009) have pointed out the detrimental effect of intermetallic (IM) thicknesses superior to $5 \mu \mathrm{m}$ on interfacial strength. However, as homogeneous IM layers are usually required for enhancing mechanical behavior, this implies the generation of homogeneous temperature profiles $T=f(x, y, t)$ between solid titanium and liquid aluminum, with wellcontrolled temperature levels to favor Ti to Al diffusion, without promoting Ti fusion. In this context, lasers appear to be promising candidates for brazing Ti with $\mathrm{Al}$, because of the large range of beam shapes (circular, rectangular) and spatial profiles (uniform, top-hat, annular) which are useful means for optimizing interfacial conditions by selecting optimal heat source amplitude and distribution.

Usually, laser brazing was carried out with a classical conduction regime. However, with the objective of increasing the scanning speed, Kreimeyer et al. (2005) have optimized butt-brazing of $2 \mathrm{~mm}$-thick Ti6Al4V to AA6016 sheets with the use of a laserinduced key-hole positioned in the aluminum side, without using fluxing of the interface, and with laser offsets of $0.3-1 \mathrm{~mm}$. With the use of a combined numerical-experimental approach, they have also defined an optimum process window to induce sufficiently thick $(0.7-1.5 \mu \mathrm{m}) \mathrm{TiAl}_{3}$ intermetallic phases in key-hole regime. Similar experiments were shown recently by Song et al (2013) considering AA6061 alloy. In both cases, they have obtained $10 \%$ lower mechanical resistance during tensile testing than the base aluminum alloy. More complex geometrical configurations 
Table 1

thermo-physical and mechanical properties of T40 titanium alloy and A5754 aluminum alloy.

\begin{tabular}{|c|c|c|c|c|c|c|c|}
\hline & $T_{\mathrm{F}}(\mathrm{K})$ & $C_{\mathrm{p}}(\mathrm{J} / \mathrm{kg} \mathrm{K})$ & $\rho\left(\mathrm{kg} / \mathrm{m}^{3}\right)$ & $k_{0}(\mathrm{~W} / \mathrm{m} \mathrm{K})$ & YS (MPa) & UTS (MPa) & $E(\mathrm{GPa})$ \\
\hline T40 & 1930 & 453 & 4420 & 25 & 350 & 450 & 104 \\
\hline A5754 & 900 & 628 & 2690 & 90 & 110 & 208 & 70 \\
\hline A4043 & 820 & 628 & 2710 & 100 & 120 & 240 & 69 \\
\hline
\end{tabular}

were also tested. For instance, Vaidya et al. (2010) have considered a butt-brazing condition, but with specifically designed u-shape AA6056 samples, and a split-beam laser brazing to ensure a symmetrical contact with Ti6Al4V sheets. Last, Chen et al. (2011) have investigated the effect of a rectangular laser spot on the dissimilar assembly of Ti6Al4V to 5A06 with V-shape groove and Al12Si eutectic filler wire. In this condition, the molten filler wire wets the titanium side and is mixed with the aluminum molten side to form a brazing-welding process.

In all the studies available in the literature, the interfacial layer between $\mathrm{Al}$ and $\mathrm{Ti}$ was formed by a near stoichiometric $\mathrm{TiAl}_{3}$ serrated intermetallic with the possible occurrence of more complex compounds such as $\mathrm{Ti}_{7} \mathrm{Al}_{5} \mathrm{Si}_{12}$ when additional $\mathrm{Al}-\mathrm{Si}$ material was used during the welding-brazing process, as evidenced by Chen et al. (2011).

Following these works, a rather simple lap-joint configuration was chosen to form Ti/Al interfaces by a laser-induced melting in conduction regime ( $\approx$ without key-hole formation), at relatively low scanning speed in order to favor liquid aluminum - solid titanium inter-diffusion. Two materials have been selected: a lowalloyed T40 titanium, and an Al-Mg alloy (A5754) for which no preliminary study on $\mathrm{Ti} / \mathrm{Al}$ joining exists. Moreover, and for the first time, such Ti/Al interfaces were used for testing the LASAT bond strength technique on dissimilar joints.

\section{Materials and experimental conditions}

\subsection{Materials}

T40 titanium alloy $(\mathrm{Ti}-0.1 \mathrm{Fe}-0.01 \mathrm{~N})$ and A5754-H111 (Al-3.2 Mg-0.4Fe-0.4Si-0.5 Mn-0.3Cr) aluminum alloy were selected to evaluate the potential of the laser-induced reactive wetting technique in overlap condition, with or without using A4043 (Al-5Si) filler wire. $100 \mathrm{~mm} \times 100 \mathrm{~mm} \times 1.5 \mathrm{~mm}$ sheets were used for assemblies, with a $1.2 \mathrm{~mm}$ diameter wire for A4043. Thermo-physical properties of the three alloys considered are presented here below (Table 1 ).

\subsection{Laser brazing conditions}

Ti to $\mathrm{Al}$ assemblies were carried out in overlap condition, with a $15 \mathrm{~mm}$ overlap distance between aluminum and titanium, and the aluminum sheet positioned on top of the titanium (Fig. 1). A $2.4 \mathrm{~mm}$ top-hat laser irradiation (10 kW Yb:YAG disk laser operating at $1.03 \mu \mathrm{m}$ ), obtained with a $0.4 \mathrm{~mm}$ optical fiber, and a factor- 6 magnification ( $100 \mathrm{~mm}$ collimating lens, and $600 \mathrm{~mm}$ focusing lens) was used to melt the aluminum, and make it spread on the titanium surface. A vertical clamping applied on two points was used in order limit deformations occurring during the brazing process, and to ensure as good as possible thermal contact between the two overlapped sheets. Prior to welding, both titanium and aluminum surfaces were fluxed to improve wetting phenomena and enhance $\mathrm{Ti}$ to $\mathrm{Al}$ diffusion by provoking a reduction of alumina $\mathrm{Al}_{2} \mathrm{O}_{3}$. This global approach was rather similar to the one used in a previous publication by Peyre et al. (2007) on aluminum-steel joining. Most of the assemblies were carried out without additive material, but a few tests were made with $\mathrm{Al}-5 \mathrm{Si}$ (5043) filler wire to estimate the influence of Si on interface formation. Experimental conditions are summarized in Table 2. To improve laser-aluminum coupling and increase the absorptivity at $\lambda=1.03 \mu \mathrm{m}$, a $5-10 \mu \mathrm{m}$ organic black paint was sprayed on the top aluminum surface. With the back paint, the absorptivity was estimated to increase from

(a)

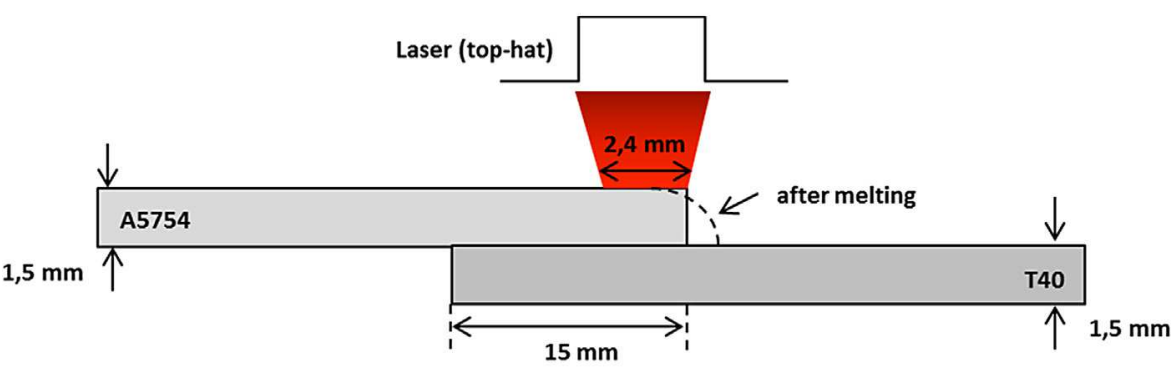

(b)

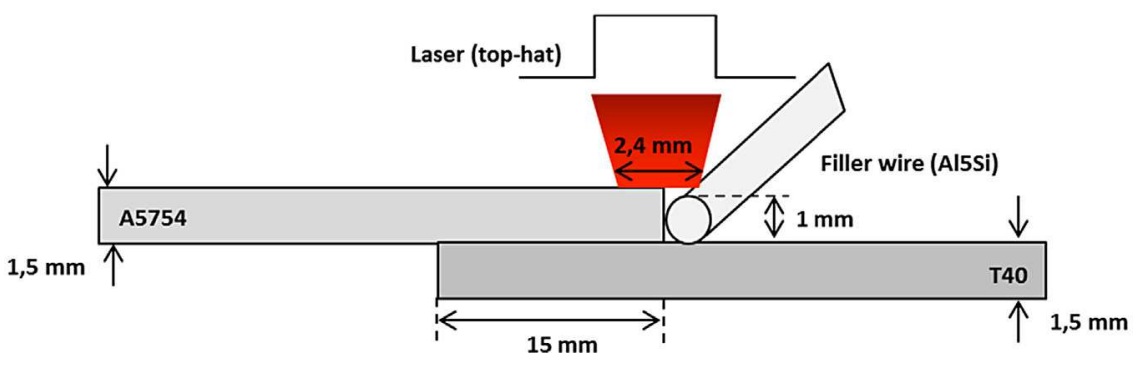

Fig. 1. Schematic drawing of the experimental joining conditions (a) without filler wire, (b) with filler wire. 
Table 2

Experimental laser brazing conditions.

\begin{tabular}{|c|c|c|c|c|}
\hline & $P(\mathrm{~W})$ & $V(\mathrm{~m} / \mathrm{min})$ & $\phi / V\left(\mathrm{~J} / \mathrm{m}^{3}\right)$ & $V_{\text {wire }}(\mathrm{m} / \mathrm{min})$ \\
\hline Without filler wire & $1500-4000$ & $0.1-0.5$ & $8.3-20 \times 10^{10}$ & - \\
\hline With A4043 filler wire & $2000-2500$ & $0.3-0.4$ & $8.9-11 \times 10^{10}$ & $1-2.6$ \\
\hline
\end{tabular}

$5 \%$ to $40 \%$. After welding, the remaining black paint was removed with ethanol. A volume energy density $\phi / V\left(\mathrm{~J} / \mathrm{m}^{3}\right)$ (with $\phi=P / S$ and $S=$ laser spot area $\left(\mathrm{m}^{2}\right)$ ) was considered as a major contributor to local heating and interface formation. Last, CCD camera observation of the welding scene was carried out at relatively low frequencies $(100-200 \mathrm{~Hz})$ with a Pixel Link camera, with the main objective of analyzing aluminum spreading.

\subsection{Metallurgical and mechanical analysis of assemblies}

After brazing, assemblies were analyzed as follows: (1) image scanning of the front and back surface of joints, (2) preparation of metallurgical cross-sections perpendicular to the joints, (3) analysis of joints and interfaces with optical and electronic microscopy (SEM-FEG Hitachi 4800 II), (4) Vickers hardness tests were carried on cross sections with a $100 \mathrm{~g}$ load, (5) tensile tests at $\mathrm{d} \varepsilon / \mathrm{d} t=10^{-3} \mathrm{~s}^{-1}$ on $20 \mathrm{~mm}$ wide samples (on each assembly, two tensile samples were machined), and (6) SEM analysis of fractures surfaces.

\subsection{The LASAT bond test}

To investigate further the mechanical resistance of joints, a novel LASAT bond analysis technique, using laser-induced shock waves, was carried out. This recently developed technique, already tested by Berthe et al. (2011) for evaluating the bond strength of paints or ceramic coating, was applied for the first time to the characterization of dissimilar weld joints. The basic principle of LASAT test is to generate a uniaxial tensile stress near the Al-Ti interface by imparting a laser-induced shock wave at the surface of the titanium sheet with the use of a nanosecond pulsed laser (Continuum Powerlite Plus, $1.5 \mathrm{~J}-10 \mathrm{~ns}-10 \mathrm{~Hz}$ ) operating in the $1-10 \mathrm{GW} / \mathrm{cm}^{2}$ range, and using the crossing of incident and reflected release waves to induce a high level tensile state susceptible to break the interface above a threshold stress value $\sigma_{\mathrm{th}}$. In turn, this technique allows obtaining the uniaxial bond strength under dynamic loading (near $10^{6} \mathrm{~s}^{-1}$ ). Additionally, with the use a VISAR (Velocity Interferometer System for Any Reflector) device composed of a laser beam probe and of a Michelson interferometer, it allows measuring free velocities $U_{\mathrm{f}}(\mathrm{m} / \mathrm{s})$ behind Ti/Al joints. This provides information about preliminary de-bonding phenomena that modify velocity time profiles $U_{\mathrm{f}}=f(t)$

Moreover, finite element simulations of shock wave propagation in the Ti/Al system were carried out on Abaqus ${ }^{\mathrm{TM}} 6.9$ explicit software, in order to determine numerically interfacial stresses $\Sigma=f(t)$. The laser-induced pressure loading applied on the T40 side was considered as a non-uniform spatial distribution of pressure $\Pi(x, y, t)=\Pi_{0} \cdot\left(1-0.5 \times{ }^{2} / r^{2}\right)^{0.5}$, as already identified by Peyre et al. (2012), and with a maximum pressure value $\Pi_{0}$ directly dependent on laser power density $\phi\left(\mathrm{W} / \mathrm{m}^{2}\right)$ according to Berthe et al. (1997).

In the Abaqus $2 \mathrm{D}$ model ( $5 \mathrm{~mm} \times 1 \mathrm{~mm})$, axisymmetric elements CAX4R were considered, with a $25 \mu \mathrm{m} \times 3 \mu \mathrm{m}$ size. Elastic-plastic properties of T40 and A5754 were considered according to Table 1, and including a strain-rate sensitivity in terms of a Johnson-Cook's law. The interface between the two materials was considered as perfect, and no fracture criterion was used in this preliminary work whereas future investigations should use direct or cumulative fracture criteria.

\section{Experimental results}

\subsection{Analysis of Ti/Al joints}

The visual inspection of Ti/Al joints globally revealed a satisfactory aspect, despite the occurrence of ripples near the aluminum side (Fig. 2), which seem to arise from a limited aluminum meltpool flow, and the presence of $\mathrm{Al}_{2} \mathrm{O}_{3}$ non-melted layer remaining on the top surface of the liquid aluminum. This alumina layer was confirmed on CCD-cameras analysis on the whole melt-pool surface, except the irradiated zone which is expected to be hotter. For a large range of experimental conditions (Fig. 3), apparently resistant assemblies were obtained, except for those carried out with insufficient laser power, for which wetting was inefficient and those carried out with excessive laser power for which titanium melting occurred and provoked a macroscopic cracking when mixed with aluminum melt-pool. The width of the fusion zone $W_{\mathrm{FZ}}$ of molten aluminum was found to be comprised between $5 \mathrm{~mm}$ and $7.5 \mathrm{~mm}$, depending on the volumetric energy $\phi / V$. However, the width of interfacial bonding $W_{\mathrm{IB}}$, determined on metallurgical cross-sections (Fig. 4), is shown to be approximately $50-70 \%$ smaller than corresponding $W_{\mathrm{FZ}}$ values. In spite of the use of fluxing to favor spreading of molten aluminum, a limited wetting width is obtained, which is expected to decrease the mechanical resistance of joints. The reason why full adhesion could not be obtained all along the FZ width $W_{\mathrm{FZ}}$ after solidification was attributed to a minimum required IM layer thickness: below $0.4 \mu \mathrm{m}$ thickness, a de-bonding occurs at the Ti/Al interface, indicating that thermally

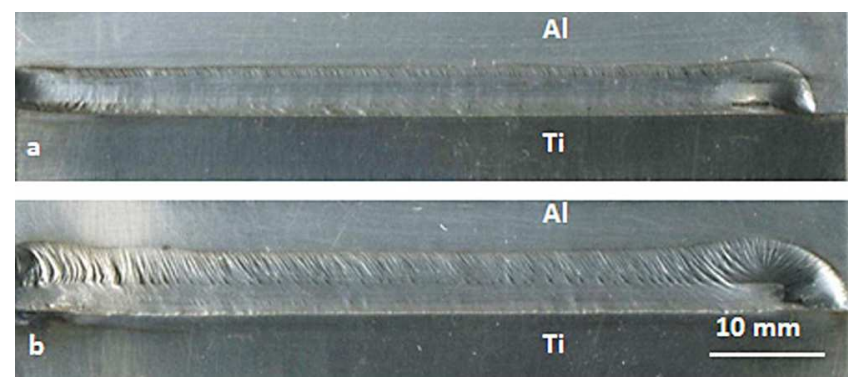

Fig. 2. Top view of Ti/Al joints (without filler wire), (a) $P=2500 \mathrm{~W}, v=0.4 \mathrm{~m} / \mathrm{min}$, $\Phi / v=8.3 .10^{10} \mathrm{~J} / \mathrm{m}^{3}$, (b) $P=1500 \mathrm{~W}, v=0.1 \mathrm{~m} / \mathrm{min}, \Phi / v=20.10^{10} \mathrm{~J} / \mathrm{m}^{3}$.

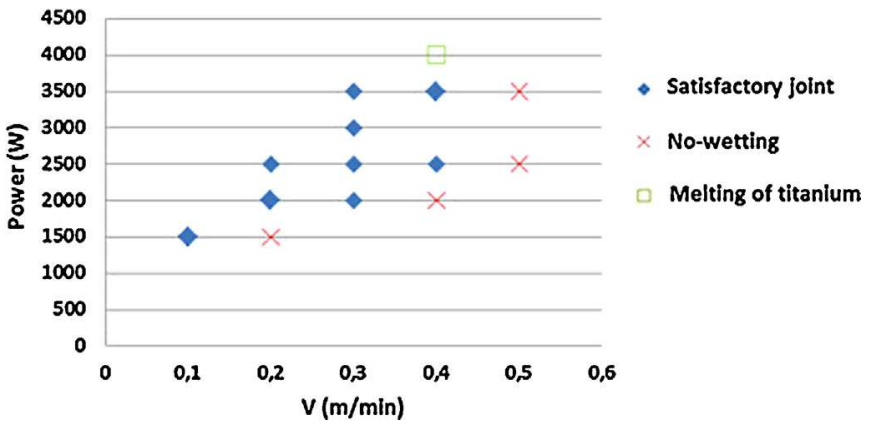

Fig. 3. Results of Ti/Al joining tests versus scanning speed $V$ and laser power $P$. At a given scanning speed, experiments carried out with insufficient power levels exhibit bad wetting whereas excessive laser power promote titanium melting. In-between these conditions, Ti/Al joints are satisfactory. 


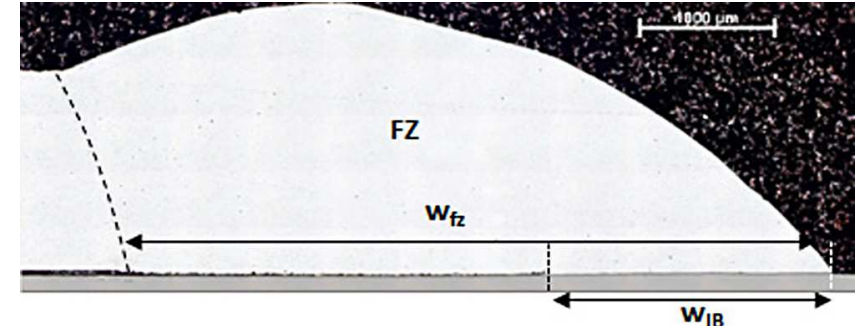

Fig. 4. Cross-section of a Ti-Al brazed joint without filler wire $(P=3500 \mathrm{~W}$, $V=0.3 \mathrm{~m} / \mathrm{min}$ ). The interfacial bonding width $W_{\mathrm{IB}}$ is less than half the total fusion zone width $W_{\mathrm{FZ}}$ of aluminum.

induced stresses during cooling and solidification have provoked an interfacial fracture. This is confirmed by the fact that IM are also present in the Al side, out of the $W_{\mathrm{IB}}$ layer.

The SEM-EDS analysis of interfacial layers indicates that a serrate-shape $\mathrm{TiAl}_{3}$ intermetallic (in-between 74.2 at\% $\mathrm{Al}-25.8$ at\% $\mathrm{Ti}$ and 75.1 at\% $\mathrm{Al}-24.9$ at\% $\mathrm{Ti}$ ) mostly forms between solid titanium and liquid aluminum, with thickness ranging between 0.5 and $2.4 \mu \mathrm{m}$, which are constantly increasing with the volumetric energy $\phi / V$ (Fig. 5). Such layers are thicker near the external edge of welds (near the maximum curvature), where the laser-induced temperature profile was higher, and tend to decrease toward the internal part of the weld. For IM average thickness below $0.5 \mu \mathrm{m}$, the IM becomes strongly heterogeneous and does not involve the whole interface. The resulting effect is that local thermal stresses generated during the phase growth and subsequent cooling have been sufficiently high to provoke interface de-bonding. The resulting effect is that molten aluminum is debonded from titanium, even if titanium has been correctly wetted. Consequently, a minimum interfacial temperature $T_{\text {int }}$ is necessary to ensure an optimal and uniform bonding between $\mathrm{Ti}$ and Al. Compared with similar reactive wetting experiments carried out on aluminum-steel joints by Peyre et al. (2007), interfacial layers were shown to be much thinner here, $(0.5-2.4 \mu \mathrm{m}$ versus 5-20 $\mu \mathrm{m}$ for rather similar conditions on $\mathrm{Fe} / \mathrm{Al}$ joints) which result highlights a difference in the mechanism of growth between the two systems. However, a more detailed explanation for this result appears to be somewhat difficult because diffusion mechanisms in the liquid state are more complicated to address than at a solid state, especially with the occurrence of convection flow in the melt-pool.

EDS analysis were performed on fusion zones (FZ) and revealed a Mg depletion ( $-1.4 \%)$, which was attributed to the high temperature level reached in molten pools that promoted $\mathrm{Mg}$ vaporization $\left(T_{\mathrm{V}}(\mathrm{Mg})=1090^{\circ} \mathrm{C}\right)$.

Reactive wetting experiments carried out with Al-5Si filler wire were also analyzed and compared with assemblies realized without filler material. For similar experimental conditions $(P, V)$, the use of a $5 \%$ Si filler wire did not produce significant modifications neither to the welds geometry, nor to the IM layer thickness or stoechiometry. However, an increase of the wire speed $V_{\text {wire }}$, and of the $V_{\text {wire }} / V$ ratio was shown to induce a doming effect, mostly visible on cross-sections (Fig. 6b). This dome-shape of the welds confirmed the rather poor wettability of titanium by molten aluminum for the experimental conditions considered here. Moreover, due to the offset of the laser spot toward the filler wire and the lower titanium (a)

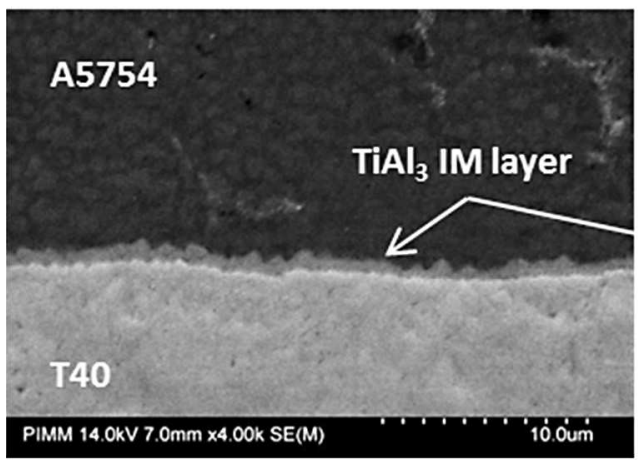

(b)

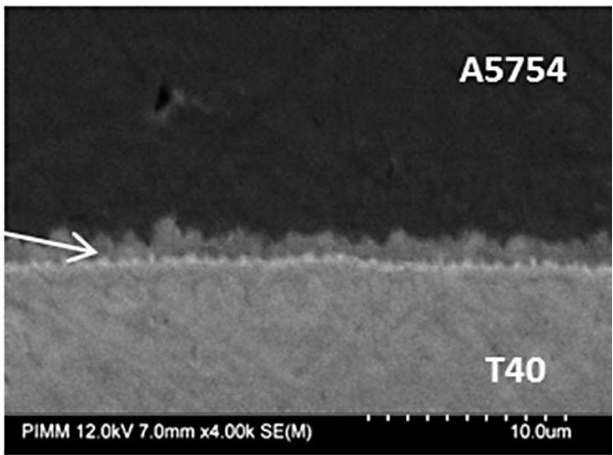

(c)

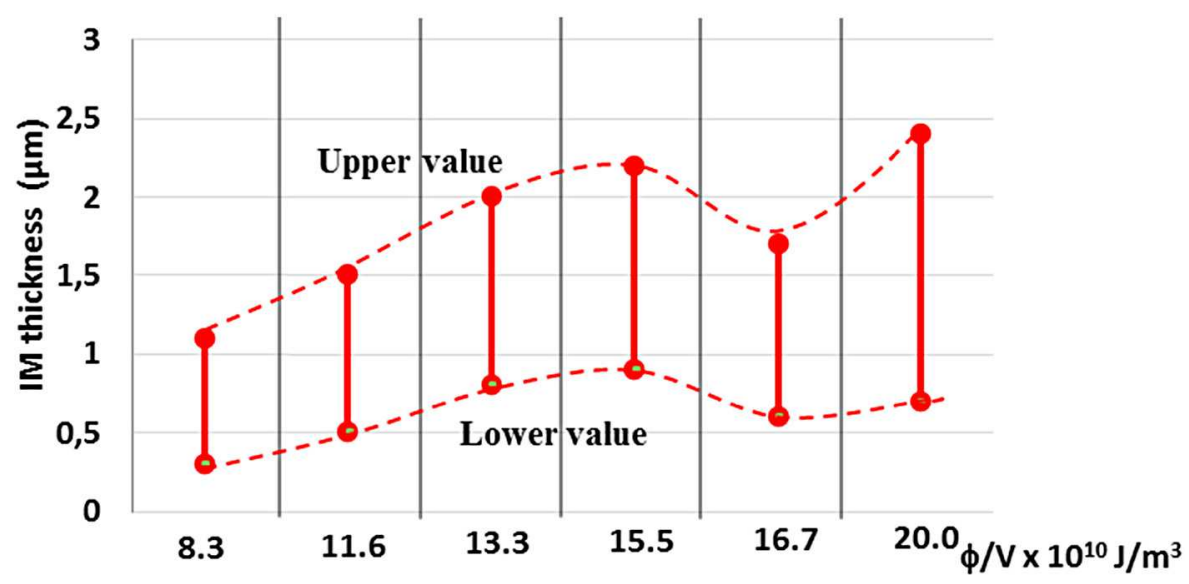

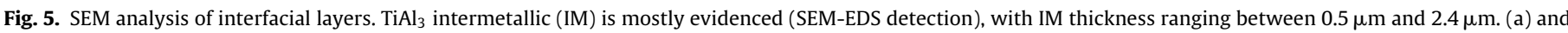
(b): $P=3500 \mathrm{~W}, V=0.3 \mathrm{~m} / \mathrm{min}$ at the internal (a) or external (b) side of the interface. (c) IM thickness versus volumetric energy $\phi / V$. 

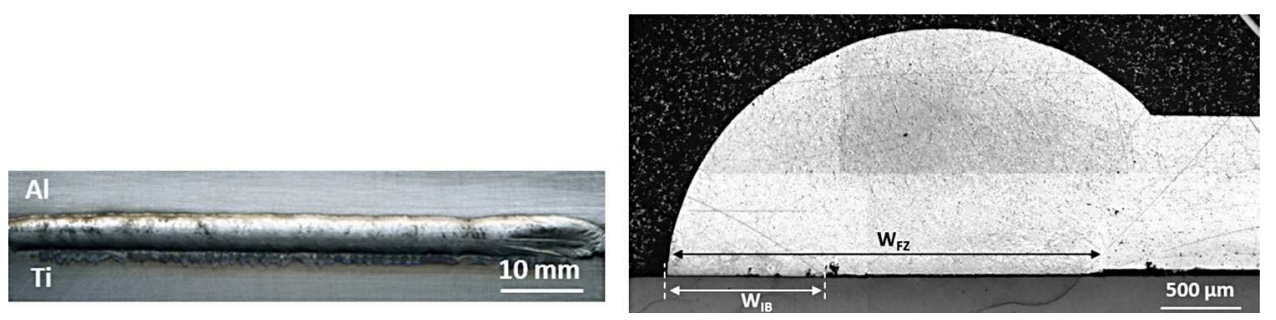

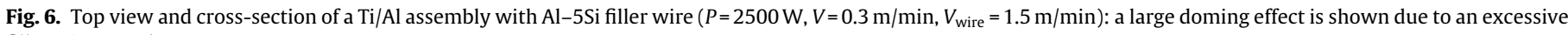
filler wire speed.

(a)

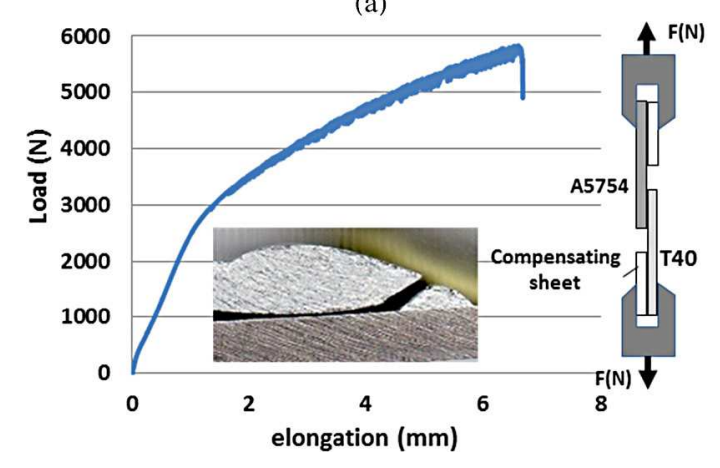

(b)

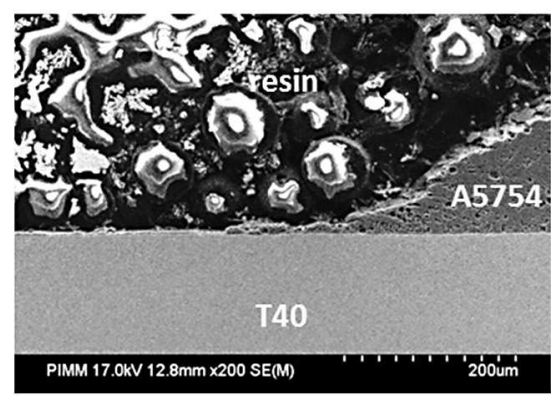

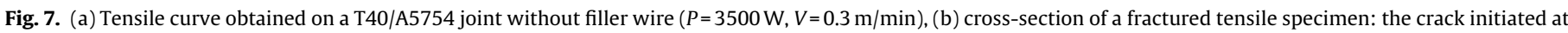

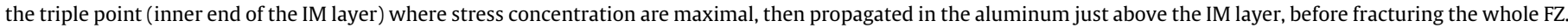

sheet (the laser was half positioned on the wire and half on the Al sheet), and due to the oscillation of the wire, local fusions of the titanium occurred that did not interact with molten aluminum but are visible on top-views (Fig. 6a).

Last, EDS analysis performed on 5754 fusion zone (FZ) revealed, as expected, a Si enrichment (+1.5\%), and a Mg depletion (-1.3\%) compared with the as-received alloy.

\subsection{Mechanical behavior of Al/Ti joints}

First of all, hardness filiations were done on metallurgical crosssections. A tiny reduction $\left(-5 \%=\right.$ from $59 \mathrm{HV}_{0.1}$ to $\left.56 \mathrm{HV}_{0.1}\right)$ of Vickers hardness was evidenced in the fusion zone of Ti/Al assemblies without filler wire, compared with the initial A5754 alloy. This softening was mostly attributed to a small amount ( $-1 \%$ ) of vaporized $\mathrm{Mg}$, which was confirmed by EDS measurements. With the use of $5 \% \mathrm{Si}$ filler wire, that increased the Si content in $\mathrm{FZ}$ up to $1-2 \% \mathrm{Si}$, a solution-solid hardening (with possible contribution from precipitation hardening) was obtained, which increased the hardness up to $80-90 \mathrm{HV}_{0.1}$. This hardening was more pronounced with higher filler wire speeds that contributed to more significant increases of the $\mathrm{Si}$ content.

Tensile tests were carried out at $10^{-3} \mathrm{~s}^{-1}$ to estimate the mechanical resistance of joints. Due to the specific shape of overlap joints, some wedges were added to the samples (Fig. 7a) to ensure as uniaxial as possible tensile loading. However, a tilt was systematically observed during the tests, so that tensile tests could not be considered as purely uniaxial. For this reason, results are not presented as $(\sigma, \varepsilon)$ curves, but instead as $(F(\mathrm{~N}), e(\mathrm{~mm}))$ curves (Fig. 7a). Consequently, mechanical strengths were given in terms of $\mathrm{N} / \mathrm{mm}$. For instance, a $5000 \mathrm{~N}$ maximum strength obtained on a $20 \mathrm{~mm}$-wide specimen corresponded to a $250 \mathrm{~N} / \mathrm{mm}$ linear resistance. A dependence of tensile resistance versus bonding width $W_{\text {IB }}$ between Ti and Al sheets was also evidenced (Fig. 8): resistances to failure increase with $W_{\mathrm{IB}}$ then saturate above $2.5 \mathrm{~mm}$. Considering a maximum linear strength of $300 \mathrm{~N} / \mathrm{mm}$ and a $2.5 \mathrm{~mm}$ wetting width, we could estimate a $120 \mathrm{MPa}$ resistance for the joints, under a complex tensile/shear loading mode. It is interesting to be noticed that such an interfacial resistance is similar to another shear strength resistance obtained by Dezellus et al. (2008) on Ti/Al-7Si interfaces studied with a classical push-out test.

Rather similar joint resistances were obtained with or without filler wire. Some $290 \mathrm{~N} / \mathrm{mm}$ maximum values were obtained, and no clear dependence versus laser conditions $(P, V)$ could be shown. For a single assembly, from which two tensile specimens were machined, a rather good reproducibility was obtained between the two tensile tests.

Because of the shape of the samples, special failure modes were shown. At the location where IM layer becomes discontinuous and does not ensure a uniform contact between $\mathrm{Al}$ and $\mathrm{Ti}$ (end of $W_{\mathrm{IB}}$ in Fig. 4), a large stress concentration usually provokes crack initiation. In a second step, the crack remains in the aluminum, but propagates at a low distance from interface. Last, in a 3rd and final step, and favored by the macroscopic tilt of the sample (compensation sheets are not efficient anymore), the fracture path deviates in

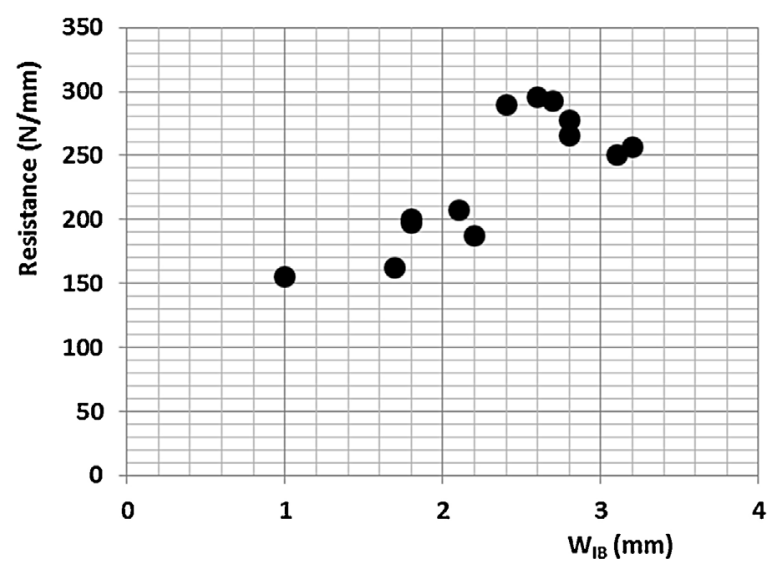

Fig. 8. Dependence of the tensile resistance versus wetting width $W_{\mathrm{IB}}$. The resistance increases, then saturates above $W_{\mathrm{IB}}=2.5 \mathrm{~mm}$. 


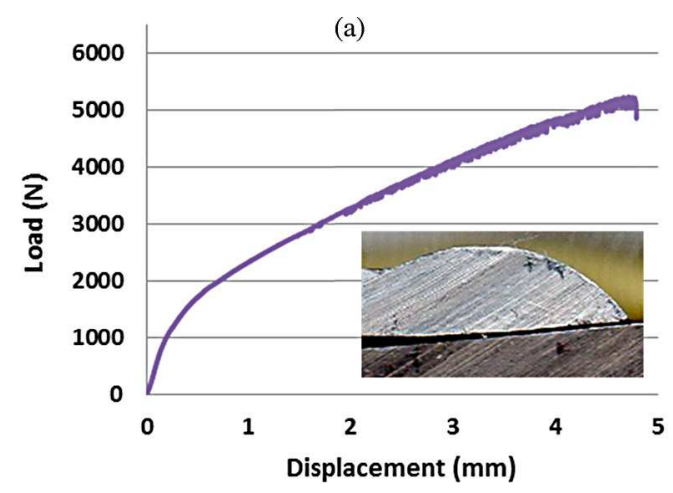

(b)

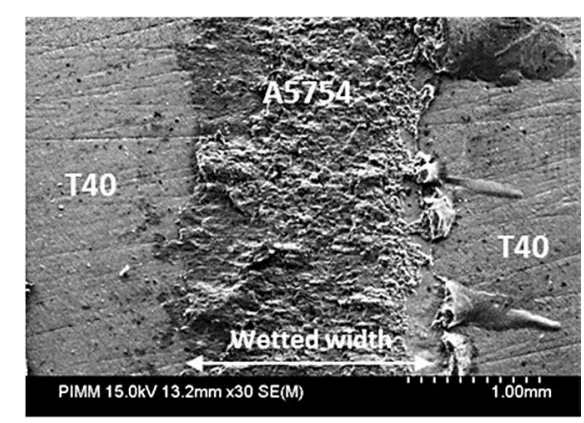

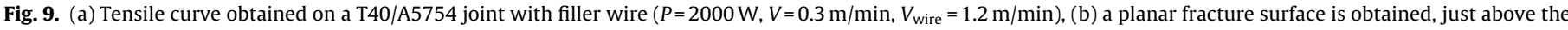
IM layer: the molten A5754 remains sticked to the T40.

the fusion zone of A5754 (Fig. 7b). In turn, such a failure came from a dual shear + tensile mode. An interesting point to notice is that $\mathrm{Ti} / \mathrm{Al}$ interfacial layers (mostly $\mathrm{TiAl}_{3}$ ) did not crack during tensile tests and always remained sound, whatever the process conditions. It was assumed that $\mathrm{T} 40 / \mathrm{TiAl}_{3} / \mathrm{A} 5754$ interface was tight and highly resistant. On a few samples (Fig. 9), the near-interface was mostly sheared, resulting in a planar fracture aspect where cracks propagated.

\section{Characterization of Ti/Al interfaces using the LASAT bond test}

\subsection{Preparation of specific Ti/Al samples}

The use of LASAT bond test is possible with or without additional diagnostic:

(1) the first and simpler method consists in submitting the (coating + substrate) system to laser impacts of increasing power densities $\phi\left(\mathrm{W} / \mathrm{m}^{2}\right)$ in order to estimate a threshold above which a visible decohesion occurs (like a bulging effect). Combined with finite element simulation, and assuming the pressure versus poser density dependence, this allow determining bond strengths;

(2) the second method combines the first one, with a VISAR velocity diagnostic which is used for probing the back free surface of the (coating + substrate) system. A change in the back free velocity time profile $U_{\mathrm{f}}=f(t)$ usually reveals the formation of voids or cracks in the system. This second approach is more accurate and allows determining the first steps of the interfacial decohesion, even in cases where bulging cannot be directly evidenced.
The use of LASAT bond test combined with VISAR velocimetry requires several interface properties for being applied accurately: first, interfaces need to be planar and sufficiently large (a few $\mathrm{mm}$ ) for performing VISAR measurements with a $0.3 \mathrm{~mm}$ diameter argon laser probe beam. Another important aspect to address is that front and back face of the assembly must be parallel so that shock wave propagations could accelerate the back free surface of the assembly in the direction opposite to the probe laser beam. Moreover, the thickness of the global assembly must be low enough to favor high interfacial applied stresses during the test. Consequently, our lapjoints were not found to be the best candidates for testing the LASAT technique on Ti/Al joints (interfacial zone was not wide enough, and the upper surface was convex). For this reason, a specific T40/A5754 assembly was realized in overlap condition, with a static laser irradiation on a (3 mm - diameter, $1.5 \mathrm{~mm}$ - height) A5754 lasermachined cylinder (Fig. 10), allowing after melting and spreading to obtain a $5 \mathrm{~mm}$ wide axisymmetric interfacial area. After polishing the upper aluminum part, we could obtain two parallel faces, and a (0.4 mm A5754/0.4 mm T40) system on which we could perform VISAR tests. For those tests, samples were mounted on a specific clamping device, with the aluminum side positioned toward the Ar probe laser, and the T40 side toward the shock generator laser (Fig. 11). The thermo-hydraulic finite element simulation of this wetting was also carried out and is available in Dal and Peyre (2013).

\subsection{Experimental testing of Ti/Al interfaces}

During the VISAR test, the Nd:YAG laser generates a high pressure plasma of $\Pi_{0}$ amplitude on T40, which globally accelerates the Ti/Al system, and its back free surface (the Al side). This acceleration of the back free surface provokes a Doppler shift $\Delta \lambda$ of the Argon probe wavelength, which is directly dependent on the free (a)

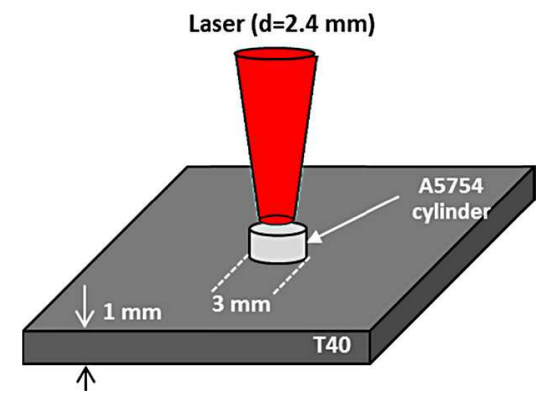

(b)

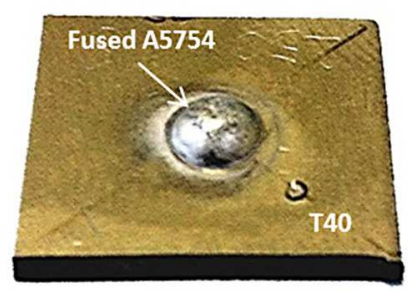

(c)

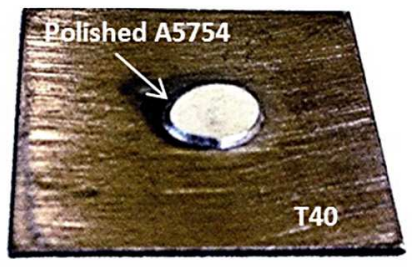

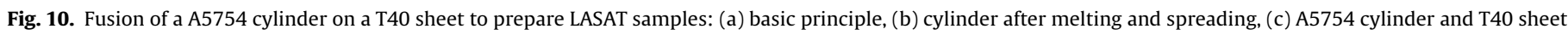
after melting-spreading and re-polishing on two sides: a system composed of $0.4 \mathrm{~mm} \mathrm{T40/0.4} \mathrm{mm} 5754$ is obtained, with a planar interface. 

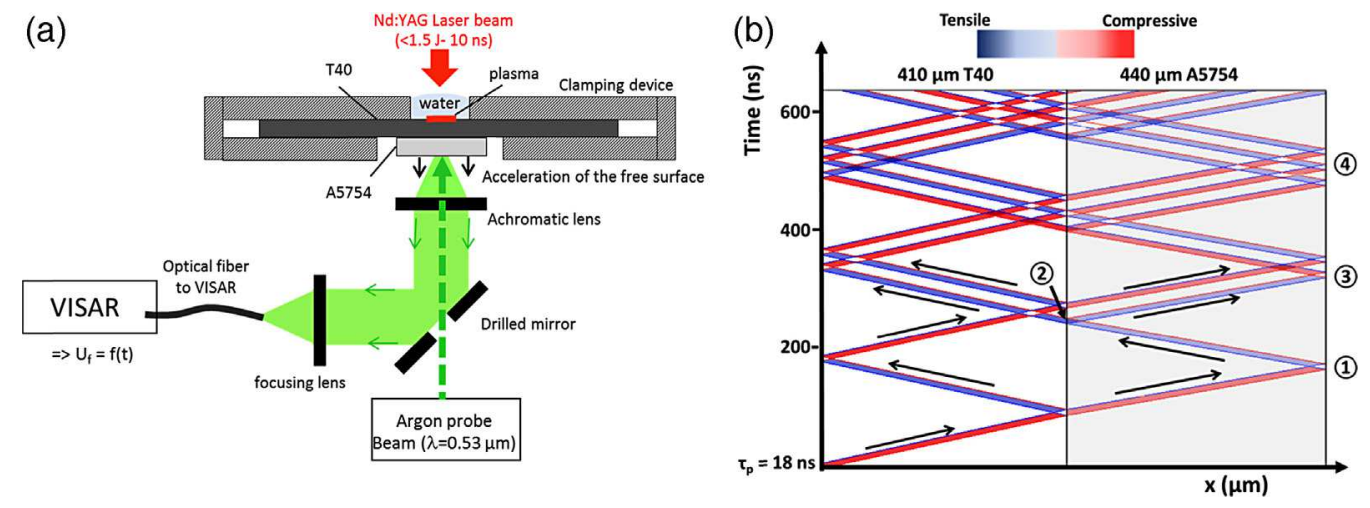

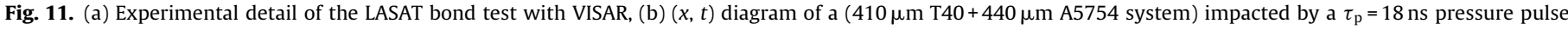
$(\approx 9-10$ ns laser pulse): a high amplitude tensile state is generated at the interface after 230 ns (point 2 ), by the crossing of incident and reflected waves.

(a)

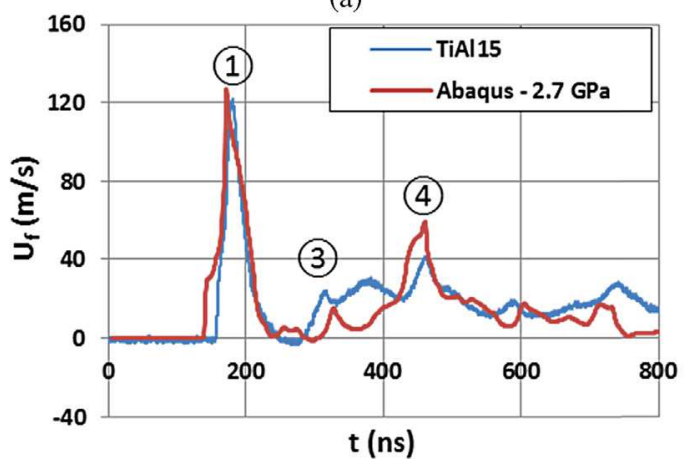

(b)

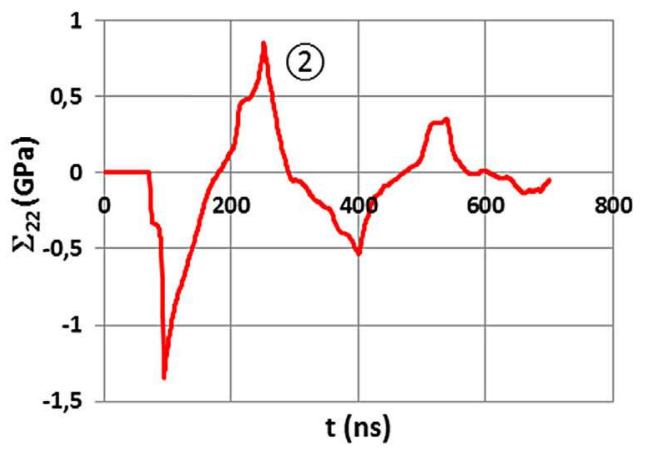

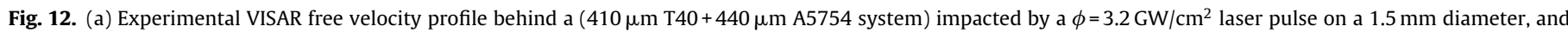

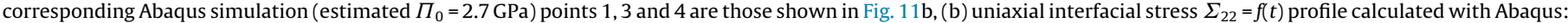
a maximum $\Sigma_{22}=0.81 \mathrm{GPa}$ value is obtained.

velocity $U_{\mathrm{f}}(t)$ on a large range of time (a few $\mu$ ). This method allows obtaining $U_{\mathrm{f}}(t)$ signals corresponding to the velocity of the center of the polished A5754 cylinder. In case of a modification of Ti/Al interfacial conditions (formation of voids or cracks), a modification of the $U_{\mathrm{f}}=f(t)$ profiles will systematically occur, usually in terms of a reduction a the velocity amplitude. With the use of finite element simulations, or simple $(x, t)$ shock propagation diagrams (Fig. 11b), the localization of tensile stresses at the interface becomes possible, mostly due to the crossing between release waves reflected on the back free surface, and the incident release wave that follows the incident shock wave.

Two A5754 cylinder/T40 sheet assemblies were tested with the LASAT method, including 5-7 tests on each assembly. Prior to each assembly, A5754 cylinder were fluxed, in order to favor spreading, and ensure as large as possible $\mathrm{Al} / \mathrm{Ti}$ interfaces. $\mathrm{A}(P=2000 \mathrm{~kW}$, $\tau=1 \mathrm{~s})$ laser pulse was used to melt and spread $\mathrm{Al}$ on the first assembly, and a $(P=2500 \mathrm{~kW}, \tau=1 \mathrm{~s})$ pulse for the second assembly.

LASAT tests were made as follows: several laser-induced shock waves with increasing pressure values were submitted in the T40 side, on the same location, until a reduction of free velocity was obtained at a $\Sigma_{\text {th }}$ interfacial value, for which a damaging of the interface was considered. This approach, somewhat similar to the well-known stair-case method used for fatigue testing, assumed that shock waves inducing lower interfacial amplitudes than $\Sigma_{\text {th }}$ ( $\Sigma<\Sigma_{\text {th }}$ ) did not have significant effect (beneficial or not) on the interfacial behavior.

An example of experimental and simulated velocity profiles is shown in Fig. $12 \mathrm{a}$, for a $\phi=3.2 \mathrm{GW} / \mathrm{cm}^{2}\left(\Pi_{0}=2.7 \mathrm{GPa}\right)$. The first velocity peak exhibits a $128 \mathrm{~m} / \mathrm{s}$ amplitude (point 1 ), and is followed by reflected peaks (points 3 and 4). Abaqus reproduced rather well those first three peaks of the velocity profile, and we could determine numerically the interfacial stress profile (Fig. 12b). Calculations indicated that a $0.81 \mathrm{GPa}$ maximum uniaxial tensile stress was applied near the Ti/Al interface during the laser-shock loading.

Using the same procedure for increasing applied pressures, the bond strength of T40/A5754 joints under mode I loading was obtained.

This bond strength was estimated to $\Sigma_{22}^{\text {th }}=0.68$ GPa (Fig. 13), which can be considered as a relatively high value for a metal-metal bond strength, especially compared with the tensile strength of assemblies (0.12 GPa in Section 2.2). However, it has to be reminded that laser-shock waves generate ultra-high dynamic deformation

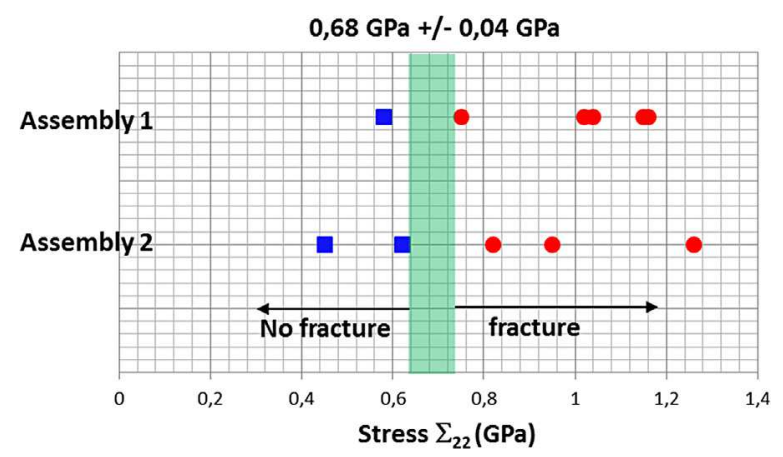

Fig. 13. Experimental determination with VISAR of T40/A5754 bond strength. Each spot corresponds to the calculated $\Sigma_{22}$ value of an experimental VISAR experiment. Above $\Sigma_{22}=0.68 \mathrm{GPa}$, corresponding to a maximum applied pressure of approximately $\Pi_{0}=2.2 \mathrm{GPa}$ on the front T40 face, a reduction of the maximum velocity $U_{\mathrm{f}}$ $(\mathrm{m} / \mathrm{s})$ is systematically observed on VISAR signals. 
$\left(10^{6} \mathrm{~s}^{-1}\right)$ that tend to increase adhesion values compared with a quasi-static loading (scratch tests, interfacial indentation).

On the one hand, the potential of the LASAT technique for analyzing dissimilar joints was clearly shown. On the other hand, the post-mortem analysis of cross-sections did not evidence macroscopic cracking near the interface, which seemed to indicate that a local fracture occurred, clearly detected by VISAR, but that no full de-bonding could be generated at the Ti/Al interface. This may be due to the limited diameter $(1.5 \mathrm{~mm})$ of laser shock loading, and the limited mechanical impulse that was not high enough to fracture entirely the interface. For this reason, future work should use higher energy lasers to provide larger spots (up to $5-6 \mathrm{~mm}$ in diameter), and higher mechanical impulses. This should allow obtaining more macroscopic interfacial de-bonding for validating velocity measurements.

\section{Conclusions}

The dissimilar laser joining of A5754 aluminum alloy with T40 titanium was first considered in lap joint condition. A brief process optimization was carried out where we used:

- fluxing for favoring aluminum spreading and wetting on T40;

- black paint for enhancing laser absorptivity A (estimated to be near 0.4 after painting) and improving the process efficiency.

Microstructural and mechanical behavior of the assemblies carried out with or without filler wire were analyzed, and concluded to a limited depletion of $\mathrm{Mg}$ in fusion zones (FZ) assumed to be due to vaporization, and to rather sound and resistant $\mathrm{TiAl}_{3}$ interface layers. The maximum resistances, obtained during tensile testing, were shown to be close to $300 \mathrm{~N} / \mathrm{mm}$, with fractures mostly occurring in the FZ, just above the intermetallic (IM) layer.

Specific T40/A5754 joints were then tested using the LASAT bond test. Combining VISAR velocity measurements to numerical simulations, we could estimate an interfacial resistance (adhesion strength) of $0.68 \mathrm{GPa}$ for a T40/A5754 joint bonded by a $2 \mu \mathrm{m}$-thick $\mathrm{TiAl}_{3}$ layer. However, it was not shown to be possible to identify precisely cracks coming from the LASAT test on post-mortem metallurgical cross-sections.

This was ascribed to various potential factors such as:

- the limited diameter of tensile zone at the interface (approximately $0.5 \mathrm{~mm}$ ) that makes difficult the identification of cracks; - possible closure effects during shock waves propagation.

\section{Acknowledgements}

This work was supported by the French CARNOT program in the frame of the ATILA project. Authors would also like to thank J. Kasemsooksakul, master student at ENSAM for helpful participation to the work.

\section{References}

Berthe, L., Fabbro, R., Peyre, P., Tollier et, L., Bartnicki, E., 1997. Shock waves from a water-confined laser-generated plasma. J. Appl. Phys. 82 (September (6)).

Berthe, L., Arrigoni, M., Boustie, M., Cuq-Lelandais, J.P., 2011. State-of-theart of laser adhesion test LASAT bond test. Non-Destruct. Test. Eval. 26, 303-317.

Chen, Y.C., Nakata, K., 2009. Microstructural characterization and mechanical properties in friction stir welding of aluminum and titanium dissimilar joints. Mater. Des. 30 (1), 469-474.

Chen, Y., Chen, S., Li, L., 2009. Effects of heat input on microstructural and mechanical property of $\mathrm{Al} / \mathrm{Ti}$ joints by rectangular spot laser welding-brazing method. Int. J. Manuf. Technol. 44 (2), 265-272

Chen, S., Li, L., Chen, Y., Dai, J., Huang, J., 2011. Improving interfacial reaction nonhomogeneity during laser welding-brazing aluminum to titanium. Mater. Des. $32,4408-4416$.

Dal, M., Peyre, P., 2013. Numerical calculation of Ti-Al assembly. In: ICALEO'13 Conference, Miami, USA

Dezellus, O., Milani, L., Bosselet, F., Sacerdote-Perronnet, M., Rouby, D., Viala, J.C., 2008. Mechanical testing of titanium/aluminium-silicon interfaces by push-out. J. Mater. Sci. 43 (6), 1749-1756.

Gupta, S.P., 2003. Intermetallic compounds in diffusion couples of Ti with an Al-Si eutectic alloy. Mater. Charact. 49, 321-330.

Kahraman, N., Gulenc, B., Findik, F., 2007. Corrosion and mechanical-microstructural aspects of dissimilar joints of Ti-6Al-4V and Al plates. Int. J. Impact Eng. 34, 1423-1432.

Kreimeyer, M., Wagner, F., Vollertsen, F., 2005. Laser processing of aluminum-titanium tailored blanks. Opt. Lasers Eng. 43, 1021-1035.

Liao, J., Yamamoto, N., Liu, H., Nakata, K., 2010. Microstructure at friction stir lap joint interface of pure titanium and steel. Mater. Lett. 64, 2317-2320.

Ma, Z., Wang, C., Yu, H., Yan, J., Shen, H., 2013. The microstructure and mechanical properties of fluxless gas tungsten arc welding-brazing made between titanium and aluminum alloys. Mater. Des. 45, 72-79.

Peyre, P., Sierra, G., Deschaux-Beaume, F., Stuart, D., Fras, G., 2007. Generation of aluminium-steel joints with laser-induced reactive wetting. Mater. Sci. Eng. A $444(1 / 2), 327-338$

Peyre, P., Berthe, L., Vignal, V., Popa, I., Baudin, T., 2012. Analysis of laser shock waves and resulting surface deformations in an Al-Cu-Li aluminium alloy. J. Phys. D: Appl. Phys. 45, 1-9.

Song, Z., Nakata, K., Wu, A., Liao, J., 2013. Interfacial microstructure and mechanical property of Ti6Al4V/A6061 dissimilar joint by direct laser brazing without filler metal and groove. Mater. Sci. Eng. A 560, 111-120.

Vaidya, W.V., Horstmann, M., Ventzke, V., Petrovski, B., Koçak, M., Tempus, G., 2010 Improving interfacial properties of a laser beam welded dissimilar joint of aluminum AA6056 and titanium Ti6Al4V for aeronautical applications. J. Mater. Sci. $45,6242-6254$ 